\title{
A HISTÓRIA PISANDO EM OVOS OU SOBRE COMO DIGERIR O PASSADO RECENTE DA HISTÓRIA DO BRASIL
}

\author{
HISTORY WALKING ON EGGSHELLS OR ABOUT HOW TO \\ DIGEST THE RECENT PAST OF BRAZILIAN HISTORY
}

\author{
Leandro Rosetti de Almeida ${ }^{1}$
}

\section{RESUMO}

Este artigo tem como objetivo discutir as maneiras como o ensino de história tem lidado com o descrédito do pensamento científico, tomando como eixo de análise o ensino da ditadura civil-militar no Brasil e as disputas de memórias e narrativas sobre este regime. Trazendo à perspectiva histórica o ensino da história da ditadura, reflito sobre como o ensino de história tem sido construído no país e o relaciona à discussão sobre a dimensão pública do conhecimento histórico. Enquanto discorro sobre limites e possibilidades do ensino de história diante das ondas negacionistas que descredenciam a ciência, destaco a história pública como uma via interessante de diálogo sobre o passado com um público mais amplo não-especializado.

\section{PALAVRAS-CHAVE}

Ensino de história; história pública; ditadura civil-militar; memória.

\begin{abstract}
This article aims to discuss the ways in which the history teaching has dealt with the discredit of scientific thought, taking as its axis of analysis the teaching of the civilmilitary dictatorship in Brazil and the disputes of memories and narratives about this regime. Bringing to the historical perspective the teaching of the history of the Brazilian dictatorship, I reflect on how history teaching has been built and relates it to the discussion on the public dimension of historical knowledge. While discussing the limits and possibilities of history teaching in the face of the negative waves that discredit science, I highlight public history as an interesting way of dialogue about the past with a broader non-specialized audience.
\end{abstract}

\section{KEYWORDS}

History teaching; public history; civil-military dictatorship; memory.

\footnotetext{
${ }^{1}$ Doutorando pelo Programa de Pós-graduação em História Social da Universidade do Estado do Rio de Janeiro (UERJ), bolsista da Fundação Carlos Chagas de Amparo à Pesquisa do Estado do Rio de Janeiro (FAPERJ). Mestre em Ensino de História (2016), egresso da primeira turma do ProfHistória/UERJ. Especialista em Gênero e Diversidade Sexual (UERJ) e em História do Brasil (Universidade Cândido Mendes). Graduou-se em História pela Universidade Federal Fluminense (2005).
} 


\section{Introdução}

O título deste artigo faz alusão a uma expressão popular cunhada para se referir aos melindres e às sutilezas necessários para se caminhar em uma dada situação. Nós "pisamos em ovos" quando caminhamos e tememos que os nossos pés macerem descuidadamente os ovos espalhados no curso a ser percorrido, de forma que se possa chegar ao destino sem que se inicie precocemente com os pés a feitura das omeletes.

A metáfora dos ovos foi evocada neste texto por três razões que são complementares. Primeiro, os ovos aqui aludem ao clássico filme de 1977, produzido por Dino De Laurentiis e dirigido por Ingmar Bergman, que no Brasil ficou conhecido como O ovo da serpente. A película recorre a uma Berlim do início dos anos 1920, com personagens tensos enfrentando dramas relacionados à depressão, alcoolismo e desemprego.

O filme popularizou a divulgação do contexto que propiciou e/ou facilitou a ascensão do nazismo na Alemanha - isto é, a serpente cujo ovo poderia ser livremente associado à sociedade da República de Weimar. E por quê? Digo, por que razão trazer o tema do nazismo à baila? Guardadas as devidas contingências que separam a Alemanha nazista do Brasil do século XXI, a proposta aqui é referenciar um contexto sociopolítico de ascensão de um pensamento conservador de extrema-direita nos últimos anos em muitos aspectos parecido com a experiência germânica.

Então, "pisar em ovos" é, antes de tudo, seguir sabendo que existem ovos cujas serpentes não apenas existem como estão sendo chocadas. Em outros termos, evocamos a necessidade de aprofundarmos a consciência de que vivemos numa sociedade estruturalmente conservadora, onde os mais extremos de seus fundamentos vêm ganhando projeção, notoriedade e aceitação.

Mas há também um segundo sentido para o título deste artigo, que tem menos a ver com os ovos do que com o cuidado em não os pisar. $\mathrm{O}$ artigo propõe uma reflexão sobre a história e, mais precisamente, sobre o ensino de história. Mais ainda, sobre a memória do ensino da história (da ditadura). A ascensão (ou a consolidação) do pensamento de extrema-direita no país trouxe inegavelmente frustrações para professores 
de história. Isto porque, como há de se ver, este modo de pensar e agir trouxe consigo a defesa de uma certa memória positiva da ditadura civil-militar. Este artigo, então, propõe examinar a história do ensino da ditadura. Ressalte-se a despretensão deste artigo de buscar culpados ou responsáveis, dentro do professorado, pelas iniciativas de exaltação das memórias saudosistas daquele regime.

O objetivo aqui é compreender o próprio fazer docente, dialogando sobre como ele tem atuado nas últimas décadas no jogo das memórias que se disputam. Apesar disso, "pisamos em ovos" porque lidamos com a memória de uma categoria profissional historicamente ultrajada - os professores - e particularmente os de história, que vêm sendo alvo de políticas persecutórias nos últimos anos, como veremos mais adiante. São trajetórias docentes inegavelmente comprometidas com a educação e com o ensino da história. Nesse sentido, sondar as memórias dessas trajetórias é sempre um processo muito delicado e de muita sensibilidade, como evidentemente o é todo trabalho que responsavelmente mobiliza memórias.

Temos, por fim, um terceiro sentido para o adágio e, de modo análogo ao segundo, tem muito a ver com o cuidado em não estragar com os pés o caminho salpicado de ovos. O contexto a que o título faz referência é precisamente ao da educação em tempos de vigilância e de denúncia contra processos de "doutrinação ideológica". Professores de história teriam se tornado "doutrinadores" em potencial. Passaram a significar ontologicamente o pertencimento aos matizes de esquerda, à adesão ao comunismo, à “degeneração moral” aliada ao combate à família tradicional e aos seus bons costumes.

Desse modo, "pisamos em ovos" quando, para lidar com temas sensíveis da história e do currículo - como escravidão, ditadura, Holocausto etc. - corremos o risco de sermos apontados como "doutrinadores" de crianças indefesas através de projetos de lei que, em última instância, defendem medidas como a denúncia e a prisão dos docentes em pleno exercício profissional. Este último sentido é particularmente interessante para este dossiê, porque as acusações contra os profissionais da história ganharam um poderoso aliado, que é o descrédito na ciência e, por consequência, em seus profissionais. Se a história e seus mestres defendem o pensamento científico - e se este é algo a ser desacreditado - então os profissionais do magistério teriam mais uma razão para serem vigiados e punidos, segundo tal perspectiva persecutória. Diante do exposto, comecemos 
a discussão a partir de um dos temas mais utilizados para identificar e apontar “doutrinadores" nas aulas de história: a ditadura civil-militar.

\section{Um passado difícil de digerir}

A indagação do historiador Marcos Napolitano (2017, p.9) é um bom começo para que aqueles três sentidos do título do artigo possam ser desdobrados e entrelaçados com o intuito de digerir (ou não) o passado recente da história brasileira. Napolitano questiona qual é o lugar da história oral e das memórias sociais no estudo da ditadura civil-militar no Brasil. A pergunta do historiador vai ao encontro das inquietudes que motivaram o presente estudo, que é o lugar do ensino de história diante do descrédito do pensamento científico.

E por que, afinal, essas duas angústias se encontram? Em primeiro lugar, porque o ensino de história aqui defendido tece profundo diálogo com a bagagem teórica e metodológica da história oral e, mais ainda, com a de sua irmã, a história pública - e em segundo lugar, porque o descrédito do pensamento científico na contemporaneidade atinge diversos campos da ciência mas, no caso da história, traduz-se em curioso desprezo pelo conhecimento historiográfico sobre a ditadura civil-militar, erigindo, em seu lugar, o sentimento de saudosismo em relação às décadas daquele regime.

Napolitano faz três considerações a respeito das memórias sobre a ditadura civilmilitar no Brasil: destaca que a longevidade do regime sedimentou muitas memórias daquela experiência histórica ainda durante sua vigência; sublinha a enorme produção acadêmica sobre o período, não necessariamente historiográfica, a partir do final dos anos 1970, ou seja, antes da abertura política; e lembra que a abertura de arquivos e a ampliação de coleções arquivísticas documentando aqueles vinte e um anos, em certa medida, podem ter contribuído para um uso tímido da história oral e das memórias em relação ao regime civil-militar, se comparado com outras experiências na América Latina.

As considerações acima nos fazem pensar sobre os caminhos alternativos que o país poderia ter trilhado no tratamento das memórias sobre a ditadura. Esta reflexão esbarra, com força, no papel que a história e o seu ensino desempenharam, poderiam ter desempenhado, ou desempenham atualmente em relação a este passado doloroso, especialmente diante das recentes e escancaradas manifestações de apoio e defesa da 
ditadura civil-militar ou de intervenções militares na sociedade e na política inspiradas no golpe de 1964.

Toda essa tensão contemporânea traz à baila três questões muito importantes - e que se alimentam mutuamente - para este estudo: a primeira, o fato de que a chamada história pública e as memórias invisibilizadas que por ela podem ser mobilizadas são fundamentais para o enfrentamento do passado doloroso do Brasil, especialmente no ensino da história; a segunda, o fato de que o descrédito sobre o conhecimento historiográfico atinge outras áreas, espaços e tempos para além da ciência histórica, do Brasil e da contemporaneidade; e a terceira, é que esse descrédito em relação ao pensamento científico/historiográfico tem encontrado um poderoso antagonista, que é crença depositada sobre a história de que ela seria suficiente e/ou necessária para explicar a conturbação dos nossos dias. ${ }^{2}$ Essas questões se alimentam mutuamente porque, nos três casos, parece ser central o fato de que a história não caminha isolada no mundo nem isolada em sua própria tradição, nem isolada dos outros campos do conhecimento, nem isolada quanto ao público que a mobiliza.

\section{Pisando em ovos: o ensino da história da ditadura}

Existem duas possibilidades para quem caminha pisando em ovos: ou ceder ao temor da quebra das cascas, ou arriscar seguir no caminho com os devidos riscos inerente ao curso. Em tempos de anti-intelectualismo, a segunda opção significa, entre outras coisas, resistir às vozes que apontam a atividade intelectual e a ciência como substratos "degenerados" de uma sociedade "sem moral”, "sem Deus", "sem família" etc. Nesse sentido, significa insistir e investir mesmo na atividade intelectual e na ciência, ainda que sob o risco de se quebrarem ovos ligados à sensibilidade profissional da categoria professor. Isso significa refletir a partir de eventuais críticas e assumir a ciência e suas bases como ferramenta política.

2 Sobre este assunto, Sonia Wanderley (2016, p. 207) é precisa: “a função social do historiador exige que nos voltemos para uma variedade de espaços públicos nos quais a memória histórica tem desempenhado importante papel. O anseio por 'explicações históricas' que caracterizam os nossos dias, demonstra a importância que a cultura histórica adquire não apenas em estudos acadêmicos, mas, também em práticas de diferentes sujeitos sociais que se ocupam em urdir uma 'autocompreensão orientadora [de suas] ações dentro da sociedade"”. 
Uma dessas críticas destaca que a história do ensino de história é marcada, muitas vezes, por certa falta de sintonia com as bases do pensamento científico, no sentido filosófico mesmo da concepção do pensamento (KNAUSS, 2005, p.281-282). ${ }^{3}$ Algo que tem a ver com o aprofundamento do debate epistemológico na história do ensino de história. A crítica pode parecer ácida - e o é - mas ela é menos importante pelo impacto sugerido por esta falta de sintonia do que pela análise que se debruça sobre uma tal relação entre a história do ensino de história e as bases da ciência.

$\mathrm{O}$ argumento trazido pelo historiador Paulo Knauss sugere que a historiografia escolar tem investido muito mais em explicações funcionais do passado do que propriamente na natureza teórico-metodológica do pensamento científico. O estudante é levado a entrar em contato com as explicações históricas durante as aulas, mas a forma como esses conteúdos foram estruturados para estar ali raramente é explicada aos discentes, como se o conteúdo de história fosse uma coisa, e a forma como esse conteúdo se estruturou fosse outra, fosse um outro componente do currículo - que nunca dá tempo de trabalhar, inclusive.

Em outros termos, o que se percebe é mais a recorrência nas salas de aula de referenciais figurativos e muito pouco, ou quase nada, de elementos categóricos que constituem a ciência histórica. Para Knauss, a disciplina história acaba privilegiando os fatos em detrimento da base epistemológica que caracteriza o conhecimento científico sobre esses mesmos fatos.

Por outro lado, o ensino de história teria uma relativa vantagem sobre a história acadêmica, já que atrelada a uma certa dinâmica empirista advinda da experiência docente, isto é, poder recorrer a diferentes modelos de explicação científica de acordo com a dinâmica da atividade docente, e explorar a diversidade de modelos de ciência.

3 "Fernando Becker estudou o universo do trabalho docente para identificar aspectos de uma teoria do conhecimento subjacente ao cotidiano da escola. O que se apresenta resumidamente é uma epistemologia do professor apriorista ou empirista, ou de caráter mesclado, sustentada, sobretudo, na prática imediata e sensorial e com base no desenvolvimento cumulativo [...]. No caso da história ensinada, pode-se dizer que a dificuldade de ciência reside propriamente na sua ausência. A história do ensino de história é demarcada por uma trajetória sem compromisso com o pensamento científico. Na verdade, ao longo dos tempos, a história ensinada no Ocidente se definiu ora por uma pedagogia da religião, ora por uma pedagogia da civilização, colocando-se entre a história sagrada e a história profana, dividindo-se entre santos e heróis. No Brasil, a história como disciplina escolar inicialmente foi marcada pelo ensino da moral religiosa e terminou se encarregando da formação cívica. De um modo ou de outro, o ensino de história desempenhou sempre um papel civilizatório, participando do processo de afirmação de projetos de identidade nacional, marcados pelo comprometimento com a inserção da sociedade do Brasil nos quadros da cultura ocidental." (KNAUSS, 2005, p.281-282) 
Dessa forma, o saber escolar demarcaria sua particularidade, "pois se permite fazer o que no campo do saber acadêmico não seria permitido: utilizar-se de diferentes formas de pensar a história sem pudores, recorrendo ao que convém no processo de ensino e aprendizagem" (KNAUSS, 2005, p.290). Para Knauss, essa diversidade científica deveria ser objeto do ensino da história, e não apenas sua metodologia.

A história da ditadura civil-militar no Brasil não escapa a essa crítica, e também tem sido mais abordada e difundida através de paradigmas figurativos e não categóricos nas salas de aula. Assim, gerações têm aprendido tudo aquilo que aconteceu na ditadura, mas muito pouco sobre como esse conhecimento foi dado a conhecer, quem o construiu, de onde saíram as informações, quem pesquisou, em que circunstâncias etc.

Se mobilizadas, as categorias explicativas deste período inevitavelmente esbarrariam com a construção das memórias sobre a ditadura civil-militar, as hegemônicas e as invisibilizadas, o que parece ser fundamental para entender o impacto público que uma visão conservadora sobre o passado recente do país assume em tempos de crise, como o que levou ao impeachment de Dilma Rousseff em 2016 e todo o período que se seguiu após o impedimento, até os dias correntes.

Por outro lado, é preciso historicizar não apenas o ensino de história da ditadura, mas a própria memória da ditadura da qual os professores de história não estão apartados; antes, como sujeitos que são, trazem consigo espaços de experiência muito importantes ligados a uma memória a ser disputada dentro de um horizonte de expectativas $\left(\right.$ KOSELLECK, 2006) ${ }^{4}$ de uma nova república, orientada pela Carta de 1988 e pelo regime democrático de direito.

Não se trata, portanto, de apontar erros dos professores na lida com o ensino da ditadura, mas de entender a experiência desses docentes - especialmente os da primeira geração após a abertura política - enquanto sujeitos construtores de uma visão de país, enquanto agentes fundamentais na disputa das narrativas sobre o passado recente - papel

4 Reinhart Koselleck (2006, p.308-311) utiliza a expectativa e a experiência como categorias metahistóricas adequadas para nos ocuparmos do tempo histórico, entrelaçando passado e futuro. Para o autor, a experiência é o passado atual, um todo onde estratos de tempos anteriores estão simultaneamente presentes hoje, onde os acontecimentos passados foram agrupados e podem ser lembrados - daí a alusão à espacialidade do conceito "espaço de experiência". Por sua vez, a expectativa também se realiza no hoje; trata-se de um futuro presente voltado para o ainda não experimentado. E porque atrás da linha do horizonte se esconde o ainda não contemplado (mas possivelmente imaginado), tal como o próprio futuro, entendese mais adequado o conceito de "horizonte de expectativa" para fazer referência à expectativa de um novo espaço de experiência que ainda está para se abrir. 
que exerceu, na maioria das vezes, de modo solitário, isto é, sem uma política de estado efetiva que amparasse ou reforçasse suas iniciativas naquela disputa de narrativas sobre o passado.

E mais: é preciso e precioso destacar que o ensino de história é uma dentre muitas frentes de disputa de memória em relação à ditadura civil-militar. Talvez seja a mais frágil delas. Na balança das narrativas, entram no jogo as memórias familiares, a cultura histórica local, o jornalismo impresso e televisionado, a produção cinematográfica, as novelas e séries, e mais recentemente a Internet e as redes sociais. Com os professores de história - quer seja através de explicações categóricas ou figurativas - o tempo que um estudante dispensa numa aula de história - em geral menos de duas horas semanais - está em absoluta desvantagem em relação ao tempo que muitos canais de comunicação ocupam na vida dos estudantes.

Quantas matérias de jornal, por exemplo, não fomentaram por anos, diariamente, a sensação de que o passado era mais seguro que o presente? Quantas manchetes não atenuaram o impacto da ditadura militar frente a violência urbana e ao "caos" da democracia $?^{5}$ Cabe aqui citar o exemplo do editorial da Folha de São Paulo que, em 17 de fevereiro de 2009, referia-se ao período em questão como "ditabranda":

Mas, se as chamadas 'ditabrandas' - caso do Brasil entre 1964 e 1985 - partiam de uma ruptura institucional e depois preservavam ou instituíam formas controladas de disputa política e acesso à Justiça -, o novo autoritarismo latino-americano, inaugurado por Alberto Fujimori no Peru, faz o caminho inverso. (Editorial, 2009).

O editorial endossa uma história da ditadura que não é a história da ditadura da escola ou, pelo menos, da maioria dos currículos. Uma ditadura que não foi tão dura assim, colocando em xeque as evidências das violações de direitos, das alterações na legislação e do próprio regime de exceção que se construiu ao longo daqueles vinte e um anos. O editorial dialoga com uma memória conservadora razoavelmente subestimada

5 Vale destacar que em muitos episódios que dialogam com a construção de uma narrativa de uma desordem que precisa ser contida ao longo da década de 1990, a intervenção das Forças Armadas foi evocada como solução para o controle da violência e da desordem. Assim, os movimentos conservadores que passaram a clamar por intervenção militar a partir de 2014 não podem ser compreendidos isoladamente, mas a partir de um lastro pavimentado de clamores por ordem e controle social. 
pelas salas de aula. Assim, a aposta é que, no afã de superar a fase anterior, a história escolar da Nova República pode ter minimizado a força de uma memória conservadora existente e remanescente a respeito do que outrora considerara sepultado.

\section{O ensino de história e a dimensão pública do conhecimento histórico}

Os exemplos acima são importantes para pensarmos o impacto público do conhecimento histórico. Oficialmente mobilizado pelos professores de história e para ampla audiência, tal conhecimento é produto também de outros agentes. De forma que o impacto público do conhecimento histórico - especialmente no caso da ditadura civil militar - não pode ser balizado e avaliado tão somente pelo sucesso ou pelo fracasso do ensino da história nas salas de aula e nas escolas. Este impacto público tem sido evocado com estudos que se inserem no que se convencionou chamar de "história pública".

O conceito é complexo, mas igualmente potente. Sua complexidade advém de sua polissemia. Ricardo Santhiago (2016, p.25-26) diz que a expressão "história pública" abarca três instâncias: a primeira, o fazer história pública - referindo-se à atuação efetiva em história pública, de modo mais pragmático; a segunda, o pensar esta área - o ato de se reunir em torno de uma agenda que reflita este campo; e a terceira, o próprio campo da história pública - a mais inovadora das três instâncias, representando menos um campo disciplinar e mais um espaço de debates com uma estrutura que tem permitido a discussão, a reflexão, a publicação e a divulgação de suas pesquisas. Nesse sentido, o que o autor defende é que essas três instâncias se articulam, permitindo que aquele conceito seja compreendido como sendo uma área de estudo onde a história é feita para/com/pelo público e também refletiria a própria relação entre história e público (2016, p.28).

Lidar com o ensino de história a partir dos referenciais da história pública equivale a conceber este ensino axiologicamente como uma espécie de "dever de memória", especialmente no caso da ditadura civil-militar. Este "dever de memória”, contudo, não será esculpido negando os obstáculos e os desafios que se apresentam. Um deles, seguramente, é o mito que confere ao professor de história a tarefa heroica de transformar o pensamento de um estudante ou, pior, de toda uma sociedade. 
O poder transformador da história na sala de aula não está em questão aqui; não se trata de negar a história enquanto uma ferramenta potente de conscientização de si e do mundo. Trata-se, no caso, de entender os limites desta transformação, posto que os elementos que mobilizam as transformações de quem quer que seja são mais profundos e enraizados do que os cinquenta minutos semanais de uma aula de história, por mais competente que seja o professor ou a professora que ministra a disciplina.

É preciso, portanto, considerar outros agentes que, com poder junto a um público amplo e diverso, disputam com a historiografia um determinado conhecimento sobre o passado: redes de televisão, filmes e séries, a grande imprensa e a imprensa alternativa, canais de vídeos da Web, além, é claro, das memórias familiares e coletivas sobre o tempo que passou. Muitas delas, indubitavelmente, invisibilizadas, negligenciadas e/ou ridicularizadas pelo conhecimento científico. Todos esses agentes estão conectados pela dimensão pública do conhecimento sobre o passado. E a história, à medida que se empodera desta dimensão pública, pode ser capaz de enfrentar, de modo consciente de seus muitos limites, as visões que escapam à verdade enquanto utopia que é pertinente à história.

Esse caminho de enfrentamento tem sido trilhado por outros campos do conhecimento científico. De forma geral, é mesmo possível dizer que toda a ciência, em seus muitos ramos, tem enfrentado vagas de descrédito de maneira coletiva, em maior ou menor grau. A desconfiança crescente sobre a ciência não é um fenômeno nem da história e nem do Brasil, em particular. A geografia e a física, por exemplo, têm sido colocadas em xeque porque suas crenças basilares simplesmente são desacreditadas.

Tanto é assim que o fenômeno mais emblemático e mais recente deste movimento contemporâneo de desconfiança é, talvez, as correntes negacionistas (DIAS, 2020) em relação à natureza e ao impacto do novo Coronavírus, causador da COVID-19. Apesar de amplamente divulgadas por sólidas instituições científicas e de saúde no Brasil e em todo o mundo, incluindo a Organização Mundial da Saúde, as correntes negacionistas têm minimizado a força da pandemia e/ou questionado a estratégia do isolamento social como medida preventiva mais eficaz na contenção da velocidade de propagação do vírus (SAKAMOTO, 2020). Ondas conspiratórias também se somaram às narrativas negacionistas, abrindo espaço para apontamentos xenofóbicos em relação aos chineses 
ou para conexões peculiares entre o Coronavírus e a disseminação do comunismo, entre muitas outras afirmações bastante descompensadas.

A questão, contudo, é: o que fazer com essa realidade? Diante do fato de a ciência, enquanto conhecimento, seguir sendo destituída de valor para uma parcela significativa da população, talvez seja o momento de a ciência (incluindo a histórica) se preocupar menos em não quebrar os ovos; ou, ao revés, de quebrá-los - mas com a preocupação de demonstrar os princípios de força, resistência, velocidade, agência, sujeito, objeto, ação e reação, que caracterizam o pensamento científico. Quebrar os ovos juntos.

\section{Quebrar os ovos juntos: possibilidades a partir da história pública}

Qual o papel da ciência diante de um movimento que se firma a partir da própria negação do pensamento científico? Que argumentos utilizar para convencer este segmento que desacredita dos princípios mais elementares do pensamento científico? E, principalmente, como se aproximar deste público sem esbarrar com a tentação da ridicularização?

Em um artigo recente, Jurandir Malerba (2016) percorre um caminho interessante de análise sobre como os historiadores têm lidado com o seu público. Examinando um artigo de Jonathan Rose, em que este tentava explicar como vários intelectuais, ao longo das gerações, tentavam discernir como mensagens ideológicas dos livros chegavam aos seus respectivos leitores, Malerba destaca que as explicações de Rose estavam todas elas atravessadas pelo que chamou de "falácia da recepção", ou seja, "o crítico admite que o que quer que o autor coloque em seu texto (...) será sempre a mensagem que o leitor comum recebe, sem estudar as respostas de qualquer outro leitor real que não o próprio crítico" (p. 138).

Se admitirmos que os críticos possam ser os pares para quem os historiadores têm escrito seus livros, artigos e ensaios, é convidativo pensar que o leitor comum não tem sido convidado a ser partícipe do processo de construção do conhecimento histórico. E se - suponhamos - a produção historiográfica em questão seja a escrita dos livros didáticos de história, convém questionar: quem seria o leitor real dessas obras? Como as mensagens desses manuais têm sido lidas por esse leitor? O que se escreve nesses livros é, de fato, o 
que este leitor lê? E quando trazemos à tona o ensino da ditadura civil-militar, como o ensino de história dialoga com a experiência desse público, com as vivências locais, com as memórias de seus familiares? Tais questionamentos dialogam com as inquietações que têm movimentado o campo da chamada história pública. Ricardo Santhiago também aposta na história pública como uma importante área de estudo que visa se aproximar (reconciliar, talvez) a história com seu público. Ele defende:

[...] a história pública como uma área de estudo e ação com quatro engajamentos fundamentais, passíveis de entrecruzamento: a história feita para o público (que prioriza a ampliação de audiências); a história feita com o público (uma história colaborativa, na qual a ideia de "autoridade compartilhada" é central); a história feita pelo público (que incorpora formas não institucionais de história e memória); e história e público (que abarcaria a reflexividade e a autorreflexividade do campo). (SANTHIAGO, 2016, p. 28)

Fazer história pública é fazer história do público e/ou para o público e/ou com o público e/ou sobre o que é público. Trata-se de trazer para o centro do espetáculo teatral, como atores, aqueles que, não há muito, eram concebidos apenas como plateia. Isto quando não eram impedidos de adentrar o sacro recinto da haute culture da historiografia. O que não significa assumir condescendência com as visões que este público traz sobre o passado, nem absorver como verdade inequívoca os testemunhos daqueles que viram a história passar, pois a história não deve se deixar trair pela tentação da memória.

É dessa maneira que a história pública é terreno fértil para se tratar o passado recente do Brasil, notadamente aquele referente às décadas da ditadura civil-militar. Tomando consciência da existência/permanência de memórias positivas em relação àquele regime, a postura mais produtiva talvez seja apostar no enfrentamento parcimonioso dessa realidade. Por que a parcimônia? Ora, a resposta é tão simples quanto complexa. Porque o enfrentamento belicoso e o combate ostensivo ao conhecimento nãocientífico sobre o passado simplesmente são inócuos.

Quem acredita na "Terra plana" não se convencerá de sua esfericidade tão somente pelos argumentos científicos energicamente defendidos por um cientista altamente gabaritado. Da mesma forma, de nada serve ao historiador comprometido com 
aquele propósito simplesmente combater com sua muito bem elaborada tese a visão de que determinado passado foi de uma maneira e não de outra. Isso vale especialmente para os estudos sobre a ditadura civil-militar no Brasil. O público que a defende, nos dias de hoje, não cederá à cientificidade do conhecimento histórico se a postura dos historiadores se reduzir à ridicularização e/ou à invisibilização.

Não pressupor que esses pensamentos não existem; não apenas existem como se fortaleceram. Aliás, é possível que tais sujeitos jamais deixem de pensar da forma como pensam. Entretanto, é possível e necessário agir para que o conhecimento historiográfico comprometido, cientificamente respaldado, conquiste potência junto ao público que, tal como na metáfora do teatro, assistia passivamente a realidade encenada. Se não for possível convencer "terraplanistas", é preciso seduzir aqueles que ainda não o são.

Se não for possível convencer os negacionistas em relação à seriedade da pandemia de COVID-19, é urgente conquistar o apoio daqueles que ainda não se dobraram ao negacionismo. Há os que jamais deixarão de afirmar que a ditadura foi a melhor fase da nossa história, mas há os que ainda não foram nem submetidos ao desprezo pelos direitos humanos e nem às fontes orais, aos depoimentos, às reportagens, e às muitas evidências que escancaram a face cruel daquelas décadas. Mas para isso é necessário considerar a existência desse público. Não obstante considerá-la, é preciso fazer com que essa existência se dê em conjunto com a pesquisa científica - talvez a razão mesma de sua existência.

O historiador Michael Frisch (2016) traduziu essa existência em conjunto ao discorrer sobre os desafios da história diante das contingências da contemporaneidade, do mundo digital e das possibilidades metodológicas que tentam acompanhar o ritmo acelerado da leitura de mundo. Ele compara os verbos explorar e buscar, enxergando mais potência no primeiro porque "sugere uma imaginação espacial não linear, em vez de linear e dirigida: pode-se habitar um espaço que está sendo explorado em vez de simplesmente forjar um caminho estreito através dele" (2016, p.66).

O juntos, por sua vez, tem muito que ver com o conceito de autoridade compartilhada, criado pelo historiador, segundo o qual "nós não somos a única autoridade, os únicos intérpretes, os únicos autores-historiadores" - e prossegue - "o processo de interpretação e de construção de significados é, por definição, compartilhado" (2016, p.62). Para o autor, o diálogo entre expertise e experiência deve 
orientar aqueles que partilham do conceito de autoridade compartilhada. Nesse diálogo é possível criar um terreno saudável, onde autoridade e autoria se confundem, se mesclam e se completam.

\section{O desafio do diálogo}

Proporcionar um diálogo verdadeiro. Criar um terreno saudável. Tratando-se da história recente do Brasil, é um desafio (na verdade, talvez o seja em qualquer situação de conflito e tensão), especialmente quando o foco são as memórias sobre a ditadura civilmilitar. É um desafio porque este é um tema sensível, um trauma histórico que precisa ser revisitado, uma ferida não cicatrizada na história do país. Como aponta Samantha Quadrat (2018, p.213), os temas sensíveis na história têm, sobre eles, a marca de um "passado que não passa, seja por conta do racismo, dos linchamentos, da ausência dos corpos das vítimas do crime de desaparecimento forçado, dos assassinatos sem respostas ou, ainda das covas coletivas".

Segundo a autora, os temas sensíveis, em geral, referem-se a eventos traumáticos ou catastróficos do século XX, embora outros exemplos anteriores - como a escravização de africanos - também possam ser contemplados por este conceito. No caso da ditadura, no Brasil, contamos com alguns fatores que colaboraram com a visão de que esse passado não deve ser "remexido". A própria anistia, tal como foi conduzida, assim como todo o “espírito cidadão" que animou a criação da Nova República, em certa medida, varreram para debaixo do tapete ${ }^{6}$ a poeira do autoritarismo, dos abusos políticos e, especialmente, da cumplicidade civil. O que significa, neste caso, criar um terreno saudável? Significa olhar para as memórias pós-abertura política e entender que algumas delas podem ter desaparecido, mas não morreram. Em outros termos, significa levantar o tapete, revolver

6 Recuperando uma imagem levantada por Marieta de Moraes Ferreira, Ricardo Santhiago sustenta que "a história oral obrigaria o historiador a enfrentar certos problemas, impedindo-o de varrê-los para debaixo do tapete [grifo nosso]. A história pública parece ter uma função paralela, e seu campo também tem servido a uma função paralela: evitar que a questão dos vários públicos da história, que perpassa toda a atividade historiadora, da pesquisa à escrita, fique encoberta" (SANTHIAGO, 2016, p. 30). 
a poeira e conseguir, sem destruir a mobília, o assoalho, a casa arrumada e o próprio tapete, dar o destino apropriado ao pó escondido. ${ }^{7}$

No caso da ditadura civil-militar, as memórias que negam a tortura ou que, na melhor das hipóteses, defendem que os métodos cruéis a que foram submetidas centenas de pessoas nas décadas daquele regime foram aplicadas porque elas mereciam - porque "bandidas", “delinquentes", “assaltantes" etc. - entram naquele escopo de narrativas que fogem ao tipo de verdade que a história almeja como norteadora de suas utopias. Entretanto, essas verdades não-históricas, alimentadas pela memória de determinados grupos conservadores e pelo testemunho individual, não deixam de ser "verdades" que dão sentido à vida dessas pessoas assim como pertencer à sociedade "terraplanista" dá sentido à vida dos adeptos deste pensamento.

Poder-se-ia dizer que esta busca de sentido que forja "verdades" as quais, muitas vezes, atentam contra a verdade-bússola que orienta a historiografia, tem se dado em um contexto de descrença no mundo tal como ele é ou como ele tem sido [transformado]. Esta desconfiança da qual a própria ciência é alvo é fruto de um deslocamento, de um desajuste, vivido por sujeitos que projetaram para o mundo as suas expectativas, com base em suas experiências, e as respostas que o mundo lhes tem oferecido, não condizentes com o que esperavam. É como se o mundo, tal como era conhecido por estes sujeitos, houvesse ruído. Sem chão, sem norte, a solução é orientar-se pelo que há de mais concreto para si e mais conhecido - o passado, que se inventa através das memórias, que se forja através das lembranças - em diálogo necessário com as carências do tempo presente. Assim, o passado ganha estatuto de verdade, respaldado pela experiência, pelo testemunho e pela memória.

E que mundo é esse que desmoronou? Longe de querer verticalizar uma discussão sobre o conceito de pós-modernidade, é inevitável trazer à discussão as transformações que afetaram econômica, social, política e culturalmente o mundo ocidental. Da pílula anticoncepcional às cotas raciais nas universidades, das ondas feministas ao advento da Aids, da queda do Muro de Berlim ao casamento igualitário, do 11 de setembro à

7 Processo que equivaleria à concepção de dever de memória consagrada por Pierre Nora e reforçada por Samantha Quadrat (218, p.213) quando anuncia que "todos nós temos como obrigação honrar e reconhecer a memória dos atingidos pelo terror, pela opressão e pela violência extrema, assim como a comunidade detentora dessa memória". 
revolução tecnológica, o mundo simplesmente se transformou, e para muitos, virou de "ponta à cabeça".

É a consagração da máxima de que "tudo que é sólido desmancha no ar", parece ser, no ano de 2020, justamente a pandemia do novo Coronavírus. Para além disso, o mundo que está "de ponta à cabeça" assiste ao surgimento de novas identidades e novos arranjos sociais e econômicos que, sem precedentes, ampliam questões como justiça social, liberdade e direito à felicidade: a organização do movimento LGBTQIA ${ }^{8}, 0$ empoderamento de mulheres negras, programas sociais como o Bolsa-Família e o acesso a bens de consumo por classes menos privilegiadas são exemplos inquestionáveis de como as últimas décadas transformaram os modos de viver.

Somado a isso, o inegável avanço da Internet, com seus muitos tentáculos aplicativos, smartphones, notebooks, televisões inteligentes, plataformas de filmes, entre muitos outros - têm diluído fronteiras físicas e simbólicas. Todo esse conjunto de fatores noticiado por uma mídia cada vez mais instantânea, que estende o quintal de cada indivíduo, em tempo real, para qualquer canto do planeta, através de uma manchete compartilhada nas redes sociais. Ou, conforme sustenta a historiadora Sonia Wanderley:

Assim, se a narrativa midiática tende a esmaecer a distinção entre passado e futuro, reforçando a ideia de um presente que se autoexplica, o resultado pode ser o fortalecimento de certa nostalgia por um passado idealizado, construído pela supervalorização dos relatos e da memória. Essa "cultura da memória" seria uma forma de compensar a perda de estabilidade que o indivíduo tem no tempo presente, uma forma de combater a profunda ansiedade com a velocidade da mudança e o contínuo encolhimento dos horizontes de tempo e de espaço que caracteriza a cultura histórica contemporânea. (WANDERLEY, 2016, p. 213)

O que Sonia Wanderley argumenta - e seguramente o diálogo com o pensamento de François Hartog (2014) aqui se nutre - é que o tempo presente tem sido alargado, grande parte pela aceleração com que as informações chegam até as pessoas. O chamado "presentismo" é um regime de historicidade caracterizado pela massificação do tempo presente, desconectando a relação temporal passado/presente/futuro - em que, para a historiadora, as mídias atuais possuem papel preponderante enquanto desarticuladoras do passado e do futuro com o presente.

8 Movimento de lésbicas, gays, bissexuais, travestis, transexuais, pessoas queer, intersexuais, assexuais e outros grupos correlatos não listados. 
Sem passado e sem futuro, a história em si perde a razão de ser. E, como o presente é lido a partir do olhar do desabono, do caos - "o mundo de ponta à cabeça" - resta às pessoas mais afetadas por este regime um enorme desprezo pelas expectativas futuras e/ou, por outro lado, uma supervalorização do tempo que passou, que era quando as coisas sólidas podiam ser compreendidas cada qual em seu lugar.

Os projetos de lei ligados ao movimento e ao programa Escola sem Partido representaram (pelo menos desde o ano de 2004, quando foi fundado aquele movimento) o esforço de combater a "desordem" desse mundo "invertido", operando a partir da escola (MOURA, 2016, p.22). Se a própria ciência passa a ser vista com desconfiança, o que não se dirá daqueles que ensinam as ciências às próximas gerações?

De mestre-com-carinho a doutrinador, de herói a inimigo, os professores especialmente os de história - teriam se transformado em agentes comunistas perigosos e associados à pedofilia [sic], ao homossexualismo [sic] e a técnicas pedagógicas bastante - digamos - criativas, como afirmava uma "denúncia" feita no ano de 2013 por uma certa assessora parlamentar, amplamente noticiada na Web em páginas religiosas (CARVALHO, 2013), referindo-se à existência de professores que supostamente orientavam crianças a beijarem meninos e meninas aos finais de semana, com o propósito de poderem, a partir da experiência, decidir com propriedade as suas orientações sexuais. Ou ainda, a alusão às mamadeiras fálicas que iniciariam crianças, desde bebês, e a partir da escola, à prática de sexo oral - conforme alertavam certas notícias há bem pouco tempo, com vistas à criação de pânico moral às vésperas das eleições de 2018. E por último, mas não menos curioso, o anúncio em vídeo da deflagração de uma nova era, onde "meninos vestem azul e meninas vestem rosa" (CERIONI, 2019).

\section{Considerações finais}

Se o próprio tempo presente é alvejado com notícias inverídicas, ou mesmo inverossímeis, e encontram ampla adesão, o que não dizer das notícias e das memórias sobre uma realidade que não mais existe, senão através dos testemunhos? Sim, pois que - por serem o que são - não estariam "corrompidos" pela ciência. No caso, a historiografia. Desconfia-se do pensamento científico e, em resposta, busca-se o apoio 
numa realidade pretérita ideal/irreal/surreal, que ganha estatuto de verdade e confere sentido à vida das pessoas, por meio das identidades que se forjam pelo ato mesmo de anunciarem seu pensamento.

Enquanto a história simplesmente aposta na pesquisa e na divulgação do conhecimento historiográfico para seus pares, essas "verdades" sobre o passado, com o potente auxílio da Internet, reproduzem-se exponencialmente, como é o caso das "verdades" sobre os "bons tempos" da ditadura civil-militar no Brasil. É por isso que a história pública se faz necessária e, mais ainda, o ensino de história como história pública. ${ }^{9}$ É porque entendemos que o conhecimento sobre o passado se difunde de e por diversos meios, que o ensino de história precisa enfrentar esses meios. Não lhes menosprezando, nem lhes invisibilizando, porque essas estratégias, tomadas conscientemente ou não, já se mostraram ineficazes.

Assim, ao virar-se para o passado recente, é preciso que a história pesquise a maneira como tem se construído, nesses muitos meios de se conhecer o passado, as "verdades" sobre a ditadura civil-militar. É preciso, por conseguinte, pesquisar como o próprio ensino de história se dedicou a estudar as décadas daquele regime. Talvez, o calcanhar de Aquiles da história ensinada tenha sido, justamente, subestimar as vozes conservadoras que jamais morreram desde que morreu o regime dos generais. Tal qual fantasmas, rondaram invisíveis aos olhos peritos dos professores e dos manuais didáticos. No momento oportuno, apareceram diante do Espelho de Clio (CARRETERO, 2010, p.17-18). E esta talvez só se livre da terrível assombração com a providência de Mnemósine, sua mãe, a deusa Titânide da memória.

Não há caminho para se lidar com a memória senão aquele repleto de ovos espalhados ao longo do tempo e do espaço. Às vezes, ovos de casca grossa - outras, ovos muito sensíveis. Às vezes, ovos geradores de regimes autocráticos - outras, ovos que guardam experiências de luta e de resistência. De todo modo, não há como fugir: não há ovo que resista ao tempo porque o destino do ovo é a eclosão.

No frigir dos ovos, pode ser este o momento de a ciência histórica tomar para si a responsabilidade de quebrá-los em vez de esperar que eles eclodam por si, porque há

9 “[...] a História escolar é, desde já, uma História Pública, embora o lugar que articule sua linguagem seja, fundamental e inequivocadamente, o ambiente do encontro pedagógico de sujeitos particulares, isto é, o lugar da escola". (ANDRADE; ANDRADE, 2016, p.181). 
serpentes que nascem destinadas a aniquilar o pensamento científico. Com sorte, na ousadia da omelete pode residir a resposta para a fome - inclusive para a fome do saber. E já que o mote culinário finda o texto ${ }^{10}$, o que se espera da história é que seus pratos não apenas sejam preparados numa via de mão única, mas igualmente servidos e degustados a partir de receitas compartilhadas. Sempre há um público disposto a provar do saber e do sabor da história, tanto quanto a contribuir com a construção de seu cardápio.

\section{REFERÊNCIAS}

ALMEIDA, Juniele Rabêlo de; MAUAD, Ana Maria; SANTHIAGO, Ricardo. (org.). História pública no Brasil: sentidos e itinerários. São Paulo, Letra e Voz, 2016.

AMATO, Gabriel.; BATISTA, Natália.; DELlAMORE, Carolina (org.). A ditadura aconteceu aqui: A história oral e as memórias do regime militar brasileiro. São Paulo: Letra e Voz, 2017.

ANDRADE, Everardo Paiva de; ANDRADE, Nívea. História pública e educação: Tecendo uma conversa, experimentando uma textura. In: ALMEIDA, Juniele Rabêlo de; MAUAD, Ana Maria; SANTHIAGO, Ricardo. (org.). História pública no Brasil: sentidos e itinerários. São Paulo, Letra e Voz, 2016. pp.175-184.

CARRETERO, Mario. Documentos de identidade: a construção da memória histórica em um mundo globalizado. São Paulo, Artmed, 2010.

CARVALHO, Renata. Denúncia: Crianças são incitadas a beijar meninos e meninas nas escolas [online]. Disponível em: $<$ http://www.portalcristaonews.com.br/2013/06/denuncia-criancas-sao-incitadasbeijar.html>. Acesso em 24 fev. 2019.

CERIONI, Carla. Menino veste azul e menina veste rosa, diz Damares em vídeo [online]. Disponível em: <https://exam3e.abril.com.br/brasil/menino-veste-azul-emenina-veste-rosa-diz-damares-em-video/>. Acesso em 24 fev 2019.

DIAS, Roberto. O Coronavírus criou uma nova espécie de negacionista [online]. Disponível em: $\quad<$ https://www1.folha.uol.com.br/colunas/robertodias/2020/04/ocoronavirus-criou-uma-nova-especie-de-negacionista.shtml > . Acesso em 28 abr. 2020.

EDITORIAL. Limites a Chávez. Folha de São Paulo. São Paulo, 17 de fevereiro. 2009. Opinião, $1^{\text {o }}$ Caderno. São Paulo, 2009. Disponível em: < https://www1.folha.uol.com.br/fsp/opiniao/fz1702200901.htm>. Acesso em: 01 ago. 2019

10 Uma referência ao artigo de Michael Frisch (2016, p.57-69), o qual conduz uma discussão sobre o papel da ciência histórica a partir do que chamou de "cozinha digital". 
FRISCH, Michael. A história pública não é uma via de mão única, ou, De $A$ Shared Authority à cozinha digital, e vice-versa. In: ALMEIDA, Juniele Rabêlo de; MAUAD, Ana Maria; SANTHIAGO, Ricardo. (org.). História pública no Brasil: sentidos e itinerários. São Paulo, Letra e Voz, 2016, p.57-69.

HARTOG, François. Regime de historicidade: presentismo e experiências do tempo. Belo Horizonte: Autêntica Editora, 2014.

KNAUSS, Paulo. O desafio da ciência: modelos científicos no ensino de história. Cadernos Cedes, v.25, n.67, p.279-295, set.-dez. 2005.

KOSELLECK, Reinhart. Futuro passado: contribuição à semântica dos tempos históricos. Rio de Janeiro: Contraponto: Ed PUC-Rio, 2006.

LAVILLE, Christian. A guerra das narrativas: debates e ilusões em torno do ensino de história. Revista Brasileira de História, v.19, n.38, pp.125-138.

MALERBA, Jurandir. Os historiadores e seus públicos: desafios ao conhecimento histórico na era digital. Revista Brasileira de História, v.37, n.74, pp.135-154.

MAUAD, Ana Maria; SANTHIAGO, Ricardo; BORGES, Viviane (org.). Que história pública queremos? São Paulo, Letra e Voz, 2018.

MOURA, Fernanda Pereira de. Escola sem Partido: relações entre Estado, educação e religião e os impactos no ensino de história. 2016. 188p. Dissertação (Mestrado em Ensino de História) - Instituto de História, Universidade Federal do Rio de Janeiro, Rio de Janeiro, 2016.

NAPOLITANO, Marcos. Prefácio. In: AMATO, Gabriel.; BATISTA, Natália.;

DELlAMORE, Carolina (org.). A ditadura aconteceu aqui: A história oral e as memórias do regime militar brasileiro. São Paulo: Letra e Voz, 2017, p. 9-13.

PROST, Antoine. A história se escreve. In: Doze lições sobre a História (trad. Guilherme João de Freitas Teixeira). Belo Horizonte: Autêntica, 2008, p.235-252.

QUADRAT, Samantha. É possível uma história pública dos temas sensíveis no Brasil? In: MAUAD, Ana Maria; SANTHIAGO, Ricardo; BORGES, Viviane (org.). Que história pública queremos? São Paulo, Letra e Voz, 2018, p.213-220.

ROCHA, Helenice A. B. A linguagem e o conhecimento no ensino de História: alternativas curriculares e didáticas. Sæculum, n 15, pp.86-96, jul./ dez., 2006.

SAKAMOTO, Leonardo. Discurso negacionista vai se adaptando e dificulta combate ao Coronavírus [online]. Disponível em: $<$ https://noticias.uol.com.br/colunas/leonardosakamoto/2020/04/10/discurso-negacionista-vai-se-adaptando-e-dificulta-combate-aocoronavirus.htm>. Acesso em 28 abr. 2020. 
SANTHIAGO, Ricardo. Duas palavras, muitos significados: Alguns comentários sobre a história pública no Brasil. In: ALMEIDA, Juniele Rabêlo de; MAUAD, Ana Maria; SANTHIAGO, Ricardo. (org.). História pública no Brasil: sentidos e itinerários. São Paulo, Letra e Voz, 2016. p.33-35.

WANDERLEY, Sonia. Narrativas contemporâneas de história e didática da história escolar. In: ALMEIDA, Juniele Rabêlo de.; MAUAD, Ana Maria; SANTHIAGO, Ricardo (org.). História pública no Brasil: sentidos e itinerários. São Paulo, Letra e Voz, 2016. pp.207-217. 